Supporting Information for the Manuscript Entitled

\title{
Polyelectrolyte Behavior of Diblock Copolymer Micelles Having Phosphonic Diacid Groups at the Corona
}

\author{
Vanessa Schmidt, ${ }^{\dagger}$ Emanuela Di Cola, ${ }^{\dagger}$ Cristiano Giacomelli, ${ }^{\dagger}$ \\ Alain R. Brisson, ${ }^{\S}$ Theyencheri Narayanan ${ }^{\dagger}$ and Redouane Borsali ${ }^{\dagger, \#, *}$
}

†Laboratoire de Chimie des Polymères Organiques (LCPO)-ENSCPB-Université Bordeaux

1, 16 Av. Pey Berland, 33607 Pessac Cedex, France;

European Synchrotron Radiation Facility (ESRF), BP220, 38043 Grenoble, France;

${ }^{\S}$ Laboratoire d'Imagerie Moléculaire et Nano-Bio-Technologie - (IECB) - Université

Bordeaux 1, 2 Rue Robert Escarpit, 33607 Pessac Cedex, France.

${ }^{\#}$ Centre de Recherche sur les Macromolécules Végétales (CERMAV, UPR 5301) and Université Joseph Fourier, BP53, 38041, Grenoble Cedex 9, France.

*borsali@cermav.cnrs.fr 


\section{Molecular Characteristics of the $P B u A_{35}-b$-PECVPD $D_{30}$ copolymer}

Table S1. Characteristics of the $\mathrm{PBuA}_{35}-b-\mathrm{PECVPD}_{30}$ diblock copolymer.

\begin{tabular}{cccccc}
\hline Copolymer & $\begin{array}{c}M_{\mathrm{n}}{\text { (target })^{\mathrm{a}}}^{(\mathrm{g} / \mathrm{mol})} \\
\mathrm{PBuA}_{35}-b-\mathrm{PDECVP}_{30}\end{array}$ & $\begin{array}{c}M_{\mathrm{n}}(\text { theo })^{\mathrm{b}} \\
(\mathrm{g} / \mathrm{mol})\end{array}$ & $\begin{array}{c}M_{\mathrm{n}}(\mathrm{GPC})^{\mathrm{c}} \\
(\mathrm{g} / \mathrm{mol})\end{array}$ & $M_{\mathrm{w}} / M_{\mathrm{n}}$ & $\phi_{\mathrm{PBuA}}{ }^{\mathrm{d}}$ \\
\hline 26900 & 11900 & 14300 & 1.16 & 0.43
\end{tabular}

${ }^{\mathrm{a}}$ At quantitative monomer conversion.

${ }^{\mathrm{b}}$ Calculated based on the conversion (33\%) estimated by ${ }^{1} \mathrm{H} \mathrm{NMR}$ in $\mathrm{CDCl}_{3}$ using mesitylene as internal reference.

${ }^{\mathrm{c}}$ Determined by GPC measurements in pure DMF at $25^{\circ} \mathrm{C}$ with poly(styrene) standards.

${ }^{d}$ Volume fraction of the PBuA hydrophobic segment.

\section{Determination of the $C M C$ for $P B u A_{35}-b-P E C V P D D_{30}$ copolymer in water}

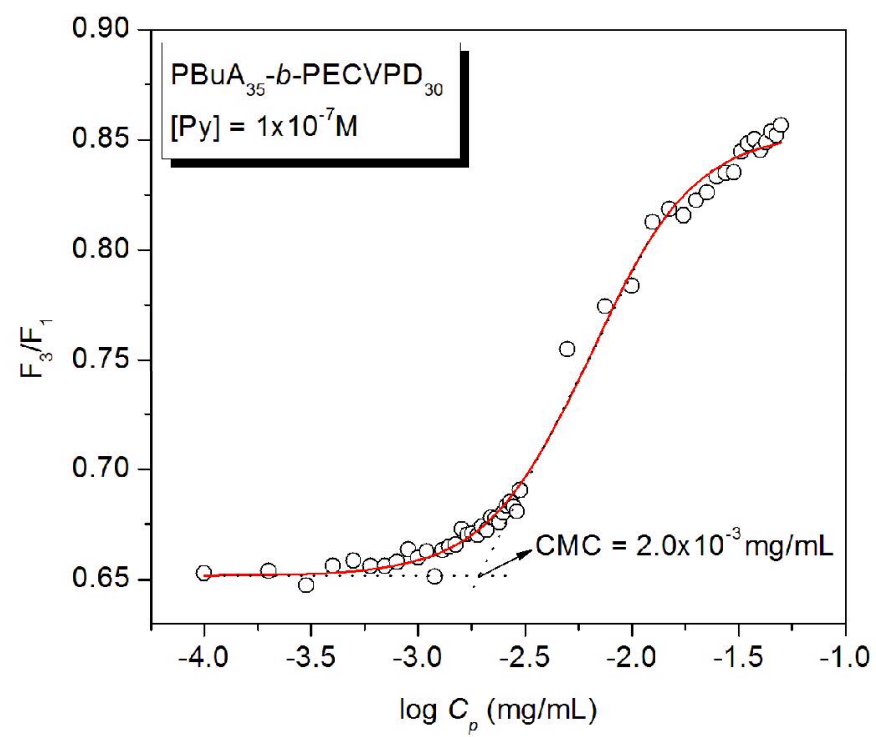

Figure S1. $\mathrm{F}_{3} / \mathrm{F}_{1}$ intensity ratios derived from pyrene emission spectra for PBuA- $b$-PECVPD copolymer solutions as a function of $C_{p}, \lambda_{\mathrm{exc}}=335 \mathrm{~nm}$. 


\section{Potentiometric titration of $P B u A_{35}-b-P E C V P D_{30}$ copolymer micellar solutions}

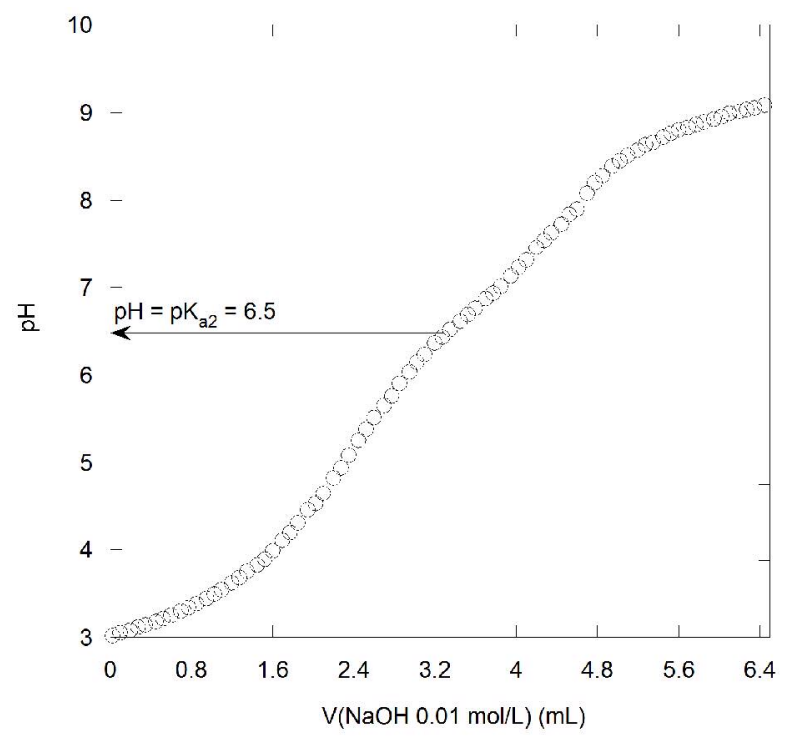

Figure S2. Potentiometric acid-base titration curves for $1.0 \mathrm{mg} / \mathrm{mL}$ PBuA- $b-P E C V P D$ copolymer solutions $\left(\mathrm{V}_{\text {aliquot }}=5.0 \mathrm{~mL}\right)$

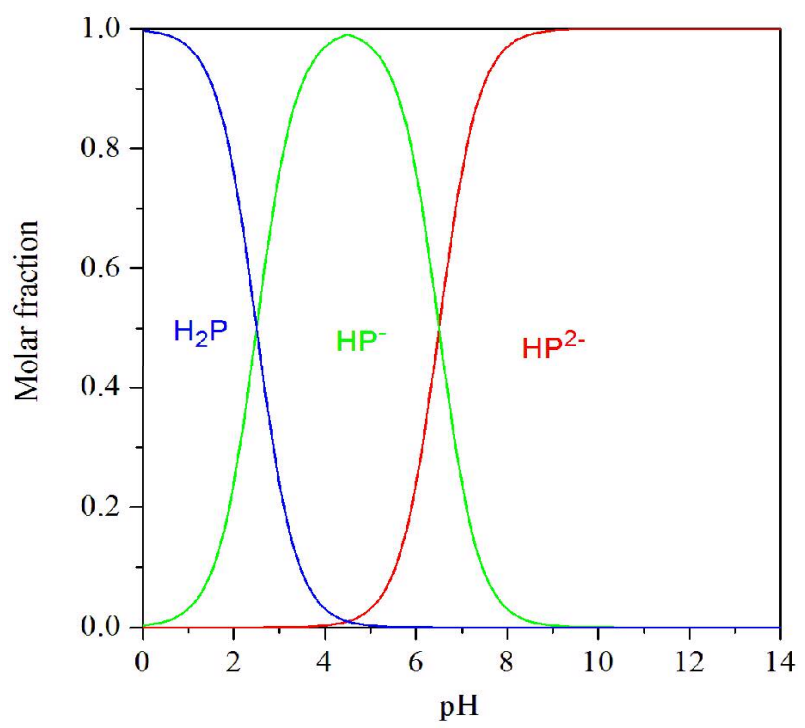

Figure S3. Diagram of species distribution as a function of the solution $\mathrm{pH}$ for a $\mathrm{H}_{2} \mathrm{P}$ ionizable polymer with $\mathrm{p} K_{\mathrm{a} 1}=2.5$ and $\mathrm{p} K_{\mathrm{a} 2}=6.5$. 


\section{TEM Experiments}

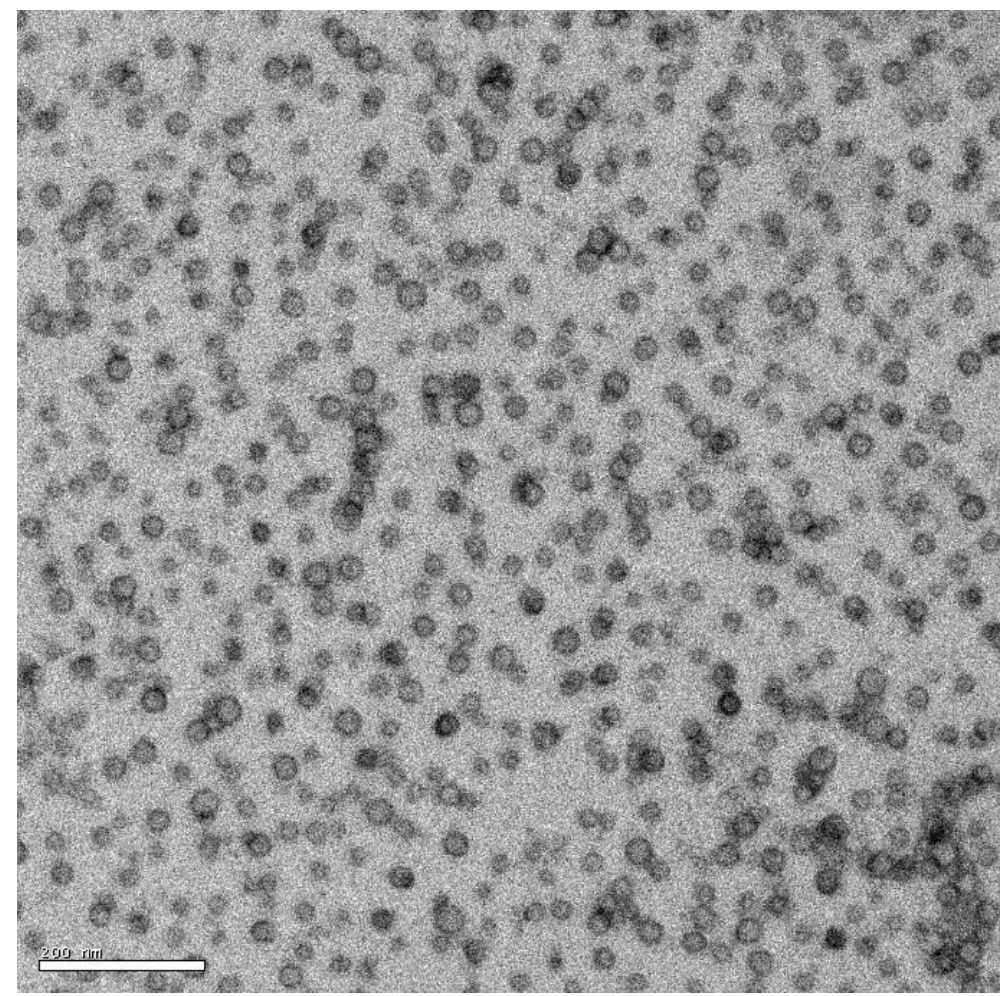

Figure S4. TEM micrograph of $0.5 \mathrm{mg} / \mathrm{mL}$ PBuA-b-PECVPD micelles in absence of added salt, and negatively stained with $2 \%$ sodium phosphotungstate solution at $\mathrm{pH}$ 7.4. (Scale bar $=200 \mathrm{~nm}$ ).
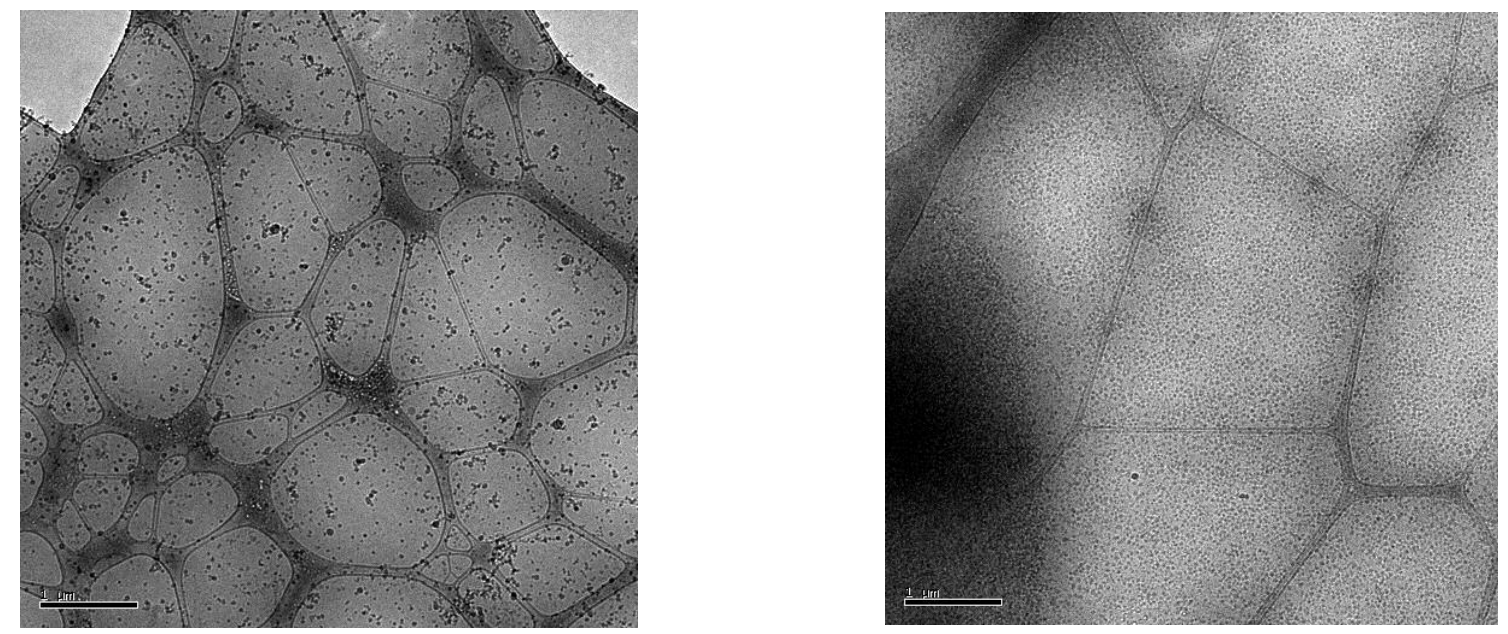

Figure S5. Cryo-TEM images of PBuA- $b$-PECVPD micelles at low magnification in absence (left) and in presence of salt $C_{\mathrm{s}}=100 \mathrm{mmol} / \mathrm{L}$ (right). 